\title{
Article
}

\section{Strategic Understandings: An Investigation of Professional Academy Youth Soccer Coaches' Interpretation, Knowledge, and Application of Game Strategies}

Price, Amy, Collins, Dave, Stoszkowski, John Robert and Pill, Shane Available at http://clok.uclan.ac.uk/33105/

Price, Amy, Collins, Dave, Stoszkowski, John Robert ORCID: 0000-0002-19685770 and Pill, Shane (2020) Strategic Understandings: An Investigation of Professional Academy Youth Soccer Coaches' Interpretation, Knowledge, and Application of Game Strategies. International Sport Coaching Journal, 7 (2). pp. 1-12. ISSN 2328-918X

It is advisable to refer to the publisher's version if you intend to cite from the work. http://dx.doi.org/10.1123/iscj.2019-0022

For more information about UCLan's research in this area go to

http://www.uclan.ac.uk/researchgroups/ and search for < name of research Group>.

For information about Research generally at UCLan please go to http://www.uclan.ac.uk/research/

All outputs in CLoK are protected by Intellectual Property Rights law, including Copyright law. Copyright, IPR and Moral Rights for the works on this site are retained by the individual authors and/or other copyright owners. Terms and conditions for use of this material are defined in the policies page. 
Running Head: STRATEGIC UNDERSTANDINGS FOR SOCCER

15

16

17

18

19

20

21

22

5

\section{7}

Strategic Understandings: An investigation of professional academy youth soccer coaches' interpretation, knowledge and application of game strategies

Date of submission: $2^{\text {nd }}$ March 2019

Date of revised submission: $30^{\text {th }}$ July 2019

8

9

0


Running Head: STRATEGIC UNDERSTANDINGS FOR SOCCER

\section{(} 7 9

Abstract

The purpose of this study was to explore professional soccer coaches' interpretations of features suggesting player game understanding across the age phases of professional academy youth soccer in England, with particular attention paid to the role of strategic understanding. Semi-structured interviews were conducted with coaches $(n=19)$ of players aged 9 to 23 to better understand how coaches understand and apply methods to develop players' strategic game understanding. Data revealed that coaches prioritized the technical and tactical development of their players over strategic development. However, across the age phases, coaches encountered challenges with coaching for strategic understanding (i.e., maintaining control of the game, players as problem solvers, player reflection, and coaching individuals within a team). We suggest that coaches and program designers need to show more intent toward developing players' strategic understanding, becoming more purposeful when choosing "how" to develop this. In particular, coaches should consider how coaching methods that seek to develop players' metacognitive game skills can be applied, with the goal of developing self-aware, flexible and independent players as learners who demonstrate an appropriately "deep" understanding of the game.

Keywords: learning; metacognition; skill; tactics; thinking

\section{8} 50 1 
Running Head: STRATEGIC UNDERSTANDINGS FOR SOCCER

Strategic understandings: An investigation of professional academy youth soccer coaches' interpretation, knowledge and application of game strategies

\section{Introduction}

The ability to understand the game is an integral component for players and teams to perform at the highest level (Davids, Araujo, Vilar, \& Renshaw, 2013; Grehaigne \& Godbout, 1998; Harvey, Cushion, Wegis, \& Massa-Gonzalez, 2010; Light, Harvery, \& Mouchet, 2014; O'Connor, Wardak, Goodyear, Larkins, \& Williams, 2018). Reflecting this importance, demonstration of skills such as reasoning, planning, strategizing and reflecting about performance (Tishman \& Perkins, 1995) are seen as indicators of "understanding." Notably, however, the process of learning such skills remains an aspect of player performance that is often difficult for coaches to navigate. One reason for this struggle might be the dynamic nature of invasion games, where players are required to execute a flexible organisation of movements to achieve performance goals (Pill, 2014). For invasion game play, performance goals are likely to emerge from both individual and team solutions for problems related to variants of both time and space, information and organisation (Grehaigne, Richard, \& Griffin, 2005). Within this complexity, a flexible performer is one whom is consistently capable of locating the optimum action for the team based upon the changing configurations of gameplay (Grehaigne, Richard, \& Griffin, 2005; Pill, 2014). In locating an optimum action, Memmert (2006) uses the "inattention blindness paradigm" to explain that conscious attention to stimuli within a dynamic context (such as soccer) also requires knowledge of situational probabilities so that decisions are made on both real-time perceptions and anticipated actions. For a soccer player, the situation is bound by flexible 


\section{Running Head: STRATEGIC UNDERSTANDINGS FOR SOCCER}

application of the game's tactical principles of play (Wade, 1967) and the internal logic of the game (Grehaigne \& Godbout, 1995, 1997), in a quest to outwit the opponent.

Principles of play provide a heuristic that enable coaches to generalize tactics both in and out of possession, while the "logic of the game" refers to tactical and strategic notions that cause interaction between "opposition to opponents, cooperation with partners, attack on the adverse camp, and defence of his own camp" (Grehaigne, Godbout, \& Bouthier, 1999, p. 8). How a player interacts with both the principles of play and the internal logic of the game is underpinned by an ongoing "oppositional relationship" existing between teams (Grehaigne, Godbout, \& Bouthier, 1999; Grehaigne, Richard, \& Griffin, 2005). In an oppositional relationship, a team's actions (and actions of players within the team) is influenced by what the opposition team (and their players) do, and thus the operational conditions of any team are to manage disorder whilst preserving some kind of order (Grehaigne, Bouthier, \& David 1997). However, understanding of how to manage an oppositional relationship is when a team (and the players in the team) are able to (deliberately) influence the opponent's next action so their response is somewhat forecasted, with the goal to cause difficult problems related to time, space, information and organisation (Grehaigne, Richard, \& Griffin, 2005). In short, players must make decisions on what they see, what they understand, what they anticipate happening and what they would like to make happen.

Furthermore, this complexity is taking place on a number of levels. In a quest to outwit the opponent, which is central to how an oppositional relationship is managed (Almond, 1986), players are required to select and apply combinations of skill, tactics and strategies on both a global level (two teams) and on partial levels (sub players or two specific players) (Grehaigne \& Godbout, 1995). To do so, Grehaigne, Godbout and Bouthier (1999) explain that strategy is planned prior to the game, on both global and 


\section{Running Head: STRATEGIC UNDERSTANDINGS FOR SOCCER}

101

102

103

104

105

106

107

108

111 tions posed by the opposition are appropriately dealt with (for a fuller definition of

112 tactics, refer to Grehaigne \& Godbout, 1995, p.491). For the player with the ball or 113 nearest the ball, these decisions will also require a degree of skill, defined by Pill (2013)

114 as "the effective application of a technique suitable to the performance outcome re-

115 quired of the moment" (Figure 4: p. 9). A definition to which we have added the word 116 in bold, since most skillful players are usually effective! In summary, invasion games 117 require a complex mix of multilayered and temporally integrated pre-planning, percep118 tion, decision making, execution and (often) on the hoof reaction; all of which works 119 well under pressure. Therefore, the challenge for coaches is to develop players who are 120 able to execute the appropriate skill in the moment, but who understand why this skill 121 is appropriate according to the desired performance outcome, so that future applications 122 of skill in a moment can be primed by previous experiences of playing games, or prior 123 knowledge about how to play games.

124 Knowledge Bases for Playing Soccer 
126 (2009), we propose that quality on field performance where players are existing within an "oppositional relationship" correlates with self-regulating qualities, such as reflec-

128 tion, planning, self-monitoring, evaluation, effort and self-efficacy. Findings from Toe-

129 ring et al. (2009) suggest that during play, elite soccer players are significantly more

130 reflective that non-elite soccer players, which is especially important for invasion

131 games players because reflection is the process that offers potential for players to think

132 strategically (Ertmer \& Newby, 1996) about how to play the game, and how to learn

133 how to play the game.

134 We argue that games (specifically soccer) offer a proportion of less time pres-

135 sured situations where there is potential for players to demonstrate a self-regulated ap136 proach toward reflection. This is when a player has a perfect opportunity to think stra137 tegically about their live game performance; importantly, the more strategic a player's 138 thought processes the more flexible their performance capability (Perkins, 1993). This

139 is because they are operating more frequently on a meta-level with conditional

140 knowledge bases which offers a greater potential to develop a deep understanding of 141 how to play the game (Toner, 2017). In games, these conditional knowledge bases re142 quire constant interaction between declarative knowledge (i.e., knowing about the pros 143 and cons of different ways in which to handle a given situation) and procedural

144 knowledge (i.e., knowing how to best execute what to do in a given situation). We argue

145 the more flexible a performer, the more they will demonstrate in-game instances of 146 strategic thinking, where actions are consciously used to outwit the opponent in order 147 to advantage the team, with particular attention paid one's own awareness of how to 148 control and regulate their own learning (see Table 1).

149 Player Understanding: Strategic Thinking in Soccer 


\section{Running Head: STRATEGIC UNDERSTANDINGS FOR SOCCER}

In this context, it is important to highlight the difference between "having a

151 strategy" and "thinking strategically" as metacognitive processes. It is likely that play-

152 ing soccer will require a collective strategy for the team to be guided by and some

153 tactical principles that will inform momentary instances as the game plays out (Gre-

154 haigne, Godbout, \& Bouthier, 1999; Richards, Collins, \& Mascarenhas, 2016). How-

155 ever, to maximise the impact of any soccer strategy or tactics, players need to use a 156 range of information sources to successfully navigate their way through a dynamic and

157 complex context, which requires players to respond to varying configurations of play

158 (Grehaigne, Richard, \& Griffin, 2005; Pill, 2014). In doing so, we suggest the sources

159 of knowledge referred to by Weinstein and Van Mater Stone (1993) is a suitable frame-

160 work to understand how a soccer player would think strategically: knowledge about

161 myself (e.g., what are my capabilities and what patterns do I notice in myself?),

162 knowledge about the task at hand (e.g., what does this task require to be successful and

163 how will success in this task be evaluated?), knowledge about strategies for learning

164 (e.g., what obstacles in the game can I remove or avoid, how can I remain motivated

165 and what can I do to remind myself of how to approach a situation?), and knowledge

166 of the game (e.g., what do I know about soccer that will help to achieve all of the

167 above?). We would also include a further category, due to the fact that soccer is an

168 interactive game which requires an oppositional relationship, and a relationship with

169 team mates; what do I know about the people playing the game (e.g., what are my team

170 mates capabilities, what are my opponent's capabilities and what patterns do I notice in 171 others?).

172 For soccer players to skilfully interact with these sources during the game re-

173 quires a high degree of control, and without managing one's own thinking in this way, 


\section{Running Head: STRATEGIC UNDERSTANDINGS FOR SOCCER}

174 it is likely that players will be operating cognitively (not metacognitively), or non-cog-

175 nitively where responses are "fast and effortless" and "apparently intuitive in nature"

176 (Toner, Montero, \& Moran, 2015), and as a result will be more reliant on the coach's

177 feedback and direction.

178 Metacognitive Game Skills

179 Reflecting the complexity of the processes described above, both metacogni-

180 tion and cognition are essential parts of player understanding. According to Flavell's

181 (1979) original explanation of metacognition, thinking about how to solve a problem is

182 used to make progress (cognitive thinking), whilst thinking about how one is thinking

183 about how to solve a problem is to monitor progress (metacognitive thinking). It is

184 essential for a soccer player to monitor their own progress as the game is being played,

185 because the game presents uncertain situations where the coach is limited to when and

186 how he/she might have an opportunity to "coach." In some ways the player themselves

187 are taking on the role of coach, if they are to effectively control how they use the sources

188 suggested by Weinstein and Van Mater Stone (1993). To control one's own thinking is

189 a complex process which requires constant adjustments of: planning (how will I ap-

190 proach this situation?), monitoring (how is this situation going, and what will I do

191 next?), and evaluating (what was the impact of how I dealt with this situation?) (Ertmer

$192 \&$ Newby, 1996). In translating this process into the context of games and, in this case,

193 soccer, Price et al. (2019) have developed three meta-cognitive game skills which indi-

194 cate a deep understanding of the game.

Metacognitive game skills happen during game play itself for practice and com-

196 petition and so, therefore, under time pressures and in situations where there is an op-

197 ponent to play against. Skills include: to plan for my/our next move, to solve and set

198 problems for the opponent, and to source new (and useful) knowledge independently 


\section{Running Head: STRATEGIC UNDERSTANDINGS FOR SOCCER}

199 (cf. Price, Collins, Stoszkowski, \& Pill, 2019). Unfortunately however, as Price, Col-

200 lins, Stoszkowski and Pill (2017) highlighted, the sport coaching literature has paid

201 little attention to the metacognitive processes associated with game play, whereas cog-

202 nitive skills such as problem solving, decision making and tactical awareness are com-

203 monly cited (Kinnerk, Harvey, MacDonncha, \& Lyons, 2018; O’Connor, Wardack,

204 Goodyear, Larkins, \& Williams, 2018).

205

\section{Metacognitive Perspectives of Game Understanding}

Due to metacognition being under-explored in the domain of expertise amongst sport performers (Dail, 2014; MacIntyre, Igou, Campbell, Moran, \& Matthews, 2014) and especially for team sport and games, the potential methods for coaching strategic understanding for soccer are limited. The exception is Price et al. (2017), whose digital video games approach (DVGA) to coaching proposes one potential "how" for coaches should they wish to enhance this element of their players' game understanding. This approach to coaching is underpinned by metacognitive theory, and originates from Gee's $(2007,2013)$ conceptual work concerning "good digital game design" where the potential for learning and performance is enhanced. The goal of the DVGA is to develop highly flexible players with strategic thought of how they understand the game. By helping players to think and act strategically via exposure to three specific metacognitive game skills (deliberate thinking and action, meta-level problem solving, good learners and teachers), Price et al. (2019) suggest that players' learning capabilities can be enhanced. However, empirical evidence supporting this hypothesis is currently lacking.

Therefore, as a first step to addressing this need, the purpose of the current study was to explore a sample of professional academy soccer coaches' interpretations of 


\section{Running Head: STRATEGIC UNDERSTANDINGS FOR SOCCER}

game understanding. Firstly, we were interested in coaches' mental models of this construct, the role of strategic understanding, and the extent to which the methods coaches used to improve this element shared common ground. Secondly, and building from these mental models, we aimed to understand how coaches at this level attempt to develop their players' strategic understanding. Finally, by introducing the concept of developing “deep understanding” (Price et al., 2019) via metacognitive coaching methods, we aimed to explore how coaches encourage their players to reflect on their thinking and understanding.

\section{Method}

As our main research question concerned soccer coaches' subjective interpretations of game understanding, the study employed an exploratory case study design as part of an overall interpretivist research paradigm for both data collection and analysis.

Qualitative data collection involved semi structured interviews, followed up with member reflections (Smith \& McGannon, 2017) to elucidate coaches' views of not just "what" and "how" to coach for game understanding but also, "why" they think this way (Abraham \& Collins, 2011).

\section{Context of the Study}

All participants in this study were professional soccer coaches in England working at the youth academy level and hence, are bound by the premier league elite player performance plan (EPPP) (Premier League, 2011), which was introduced with the aim of producing more and "better" home grown players by promoting the empowerment of each individual through a player led approach. The EPPP sets out three age phases for player development; Foundation Phase (age 9-11 years), Youth Development Phase (age 12-16 years) and Professional Development Phase (age 17-21 years). All were from professional academies at Category 1 status (x15) and Category 2 status (x4), 


\section{Running Head: STRATEGIC UNDERSTANDINGS FOR SOCCER}

working with players from a range of age phases. The EPPP outlines a total of four categories, with category 1 being deemed as "most elite." The categorisation of academies is decided by an independent audit from The Premier League concerning a range of factors including productivity rates and coaching (Premier League, 2011). Importantly, all seven of the academies involved in this study have their own coaching and playing approach, against which coaching staff and players are internally judged. For reasons of confidentiality, it is not possible to publish the coaching or playing approaches adopted by individual clubs.

\section{Participants}

There were three criteria for inclusion in the study. First, to have a recognised coaching qualification, awarded by UEFA (Union of European Football Associations) at either B (the industry minimum standard) or A (advanced) level; second, to have at least three years of experience of working with players in an academy environment; third, to be currently working with academy players on a first hand and consistent basis within the EPPP (Premier League, 2011). Initially, a number of coaches who met these criteria were recruited via email to take part in the study. Following this, a further group of coaches, who work within the Youth Development Phase, were recruited as we recognized that it was during this age phase that players move from a 9-aside game format to an 11-aside game format. Therefore, we viewed this age phase as two separate phases; 12-13 years (playing 9-aside), and 14-16 years (playing 11-aside). Thus, participants recruited per age phase were: Foundation Phase (age 9-11 years) = five participants (x4 full time and x1 part time), Youth Development Phase (a) (age 12-13 years $)=$ four participants $(\mathrm{x} 2$ full time and $\mathrm{x} 2$ part time $)$, Youth Development Phase (b) $($ age 14-16 years) $=$ five participants ( $\mathrm{x} 3$ full time and $\mathrm{x} 2$ part time), Professional 
Running Head: STRATEGIC UNDERSTANDINGS FOR SOCCER

272 Development Phase (age 17-21 years) = five participants (x5 full time), totalling 19

273 participants (all male) who all reported themselves to be British. (see Table 2).

\section{Procedure}

275 Ethical approval for the present study was granted by the University's research 276 ethics committee before informed consent was obtained from all participants. The first 277 author, who is a UEFA qualified soccer coach and FA coach educator with experience 278 of qualitative research methods, conducted all interviews to avoid inter-interview bias 279 (Lincoln \& Guba, 1985). The average duration of interviews was 67 minutes (range = 280 49-85 minutes). All interviews were audio recorded, then transcribed verbatim.

281 All interviews were conducted over a four-week period at the end of the soccer 282 season. This was a particularly convenient time as the clubs involved were in the pro283 cess of reviewing their coaching methodologies in preparation for the following season. 284 As such, the interviews encouraged coaches to be open about their club's approach 285 toward player development, and appreciative of the social and cultural challenges 286 within the environment they operate within. To aid the openness of the researcher-par287 ticipant relationship, at the beginning of all interviews the researcher reinforced the 288 confidentiality and anonymity of data, as well as participants' rights to withdraw at any 289 stage and for any reason.

290 At the start of each interview, participants were told to think of one player they

291 had coached during the season who they felt had a particularly good understanding of 292 the game compared to their teammates. For the duration of the interview, participants 293 were reminded to think of this player when responding to interview questions. Towards 294 the later part of the interview, coaches were presented with three prompts that repre295 sented principles of metacognitive game skills in action (Price et al., 2019): (1) "The 296 plan is to use this strategy, though we might need to re-plan depending on what happens 


\section{Running Head: STRATEGIC UNDERSTANDINGS FOR SOCCER}

in the game"; (2) "This is how to solve the problem we face, and we're using this solution so that the game poses problem $x$ to the other team"; and (3) "I've realized that we are finding situation $\mathrm{X}$ difficult in this game; I'm going to find new knowledge of the game to alter how I deal with this situation in the future."

The use of these specific prompts was important as a key purpose of this study was to understand how coaches perceive a "deep understanding" of the game to be represented by their players. Upon being presented with each prompt, coaches were asked to explain if and how the prompt might be an effective criterion for game understanding in soccer. Further discussion moved towards the variants of each prompt in game play (practice and competition), followed with how the coach might facilitate its development for their players. Follow up elaboration and clarification probes (e.g., can you describe what that might look like on the field with your players?') were used to encourage the coaches to describe their thoughts using practical soccer examples, to evoke a rich and meaningful dialogue, as well as strengthening understanding of what was being said (Gratton \& Jones, 2004).

\section{Data Analysis}

The first author read each interview transcript twice in order to become immersed in the data, paying particular attention to the ways that participants differentiated between technical, skill, tactical and strategic understanding of soccer. Following this, an inductive thematic content analysis was conducted which consisted of identification of higher order (global) and lower order (initial) themes, using Braun \& Clarke's six step analysis (Braun \& Clarke, 2013). These steps included: becoming familiar with the data by reading and re-reading transcripts; generating codes systematically and inclusively; generating initial, lower order themes by organising codes into clusters; re- 


\section{Running Head: STRATEGIC UNDERSTANDINGS FOR SOCCER}

viewing initial, lower order themes by looking at the data set holistically with the support from critical friends; defining and naming global, higher order themes, and finally producing the report with selection of key data extracts. During this process, key quotes were extracted from the data and classified into themes.

\section{Trustworthiness}

In order to enhance the trustworthiness of both the data collection and analysis, the following practices were utilized. To guide discussion and explore coaches constructs of game understanding, an interview schedule was designed to elicit detail of the "what," "how" and "why" of coaching soccer for understanding (see Table 3). To go beyond surface level responses from the coaches, questions were deliberately broad and open-ended (cf. Stoszkowski, Collins, \& Olsson, 2017) and the interview schedule was cross checked by all four authors against its' potential to elicit responses relevant to the purposes of the study (Cresswell, 2007). Although the order of questions asked during each interview varied slightly depending on the direction of the discussion, the same questions were asked to all 19 participants.

As Smith \& McGannon (2017) describe, using a critical friend in qualitative research has the potential to create valuable dialogue between researchers, adding rigor to the process. In the current study, the first author conducted the analysis of interview data and generated initial themes. Following this, the second, third and fourth authors were asked to provide critical feedback on the way the raw data had been interpreted and sorted into initial themes. This process helped the first author to reflect on the initial choice of themes and to explore alternatives, whilst also learning how to defend her decisions. Member reflections, which Braun and Clarke (2013) and Tracy (2010) explain go beyond simply checking that the researcher "got it right," were also used to empower participants in the data analysis process, adding both richness and depth to 


\section{Running Head: STRATEGIC UNDERSTANDINGS FOR SOCCER}

346 findings. The first author met with each participant individually following the analysis

347 of their interview to present the themes and associated extracts of data that were gener-

348 ated in the analysis. Together, first author and participant explored their interpretations

349 of the themes with extracts of data, and identified any gaps or similarities concerning

350 these interpretations. Throughout the data analysis process, the first author also re-

351 flected on her approach by writing memos in a reflective diary in order to enhance 352 reflexivity and transparency (Tracy, 2010). She then routinely presented and discussed

353 these memos with the broader research team in order to identify any personal biases

354 that may be influencing the research process. Finally, in presenting the findings from 355 the inductive data analysis, the direct quotations selected are contextually rich, and 356 taken from a range of participants within the sample. This allows the reader, based upon 357 their own coaching context, to decide on the applicability of findings concerning "game 358 understanding." cussed consistently across the age phases (see Table 4): (1) maintaining control of the game; (2) players as problem solvers; (3) player reflection and (4) individuals within a team. In the following sections, each higher order theme is presented alongside associ-

364 ated lower order themes, with exemplar quotes. Pseudonyms have been used through365 out to protect the identity of the coaches.

\section{Maintaining control of the game}

There were two lower order themes associated with this higher order theme 368 playing in a style that represents identity of the soccer club and using game plans. All game plans. All coaches identified that they were bound by their club's preference for 


\section{Running Head: STRATEGIC UNDERSTANDINGS FOR SOCCER}

playing style (in and out of possession), and that they rarely provided opportunity for players to play in a different style, both in practice and competitive matches.

Interestingly, coaches made the point that the style of play was also their game strategy e.g., "the coherence of a philosophy throughout the different ages that we play means that strategies are often the same" (Simon, u11 coach). On numerous occasions, when asked if the playing style might change during game play, coaches commented on the necessity for academy teams to play in a similar fashion. This is exemplified in the following quotes:

"I think we're quite good at the club that we do have a way of playing, and I think if you looked at our teams from under nine right the way up there is, you can see a club way." (Mark, u14 coach)

“...we're doing it for a reason, and particularly at this club, we do have a playing philosophy and as I said, there are some expectations about the way that we play... So...we've got to have those things for a reason, and hopefully it's because the coaches and the players believe in it." (Craig, u13 coach)

“...the boys will always have a strategy and a way of playing, that we like to think that we have throughout the whole academy...that might look slightly different at under nines...but as soon as that's going into eleven-v-eleven, we want to start seeing traits of what we do and what we believe in." (John, u18 coach).

The second lower order theme referred to game plans in advance of matches, specifically in relation to the role of the coach when deciding on a game plan. Several coaches related strategy to having a "plan A," which was formulated by the coach after 


\section{Running Head: STRATEGIC UNDERSTANDINGS FOR SOCCER}

video analysis of the opponent in advance of the match. The exception were the foundation phase coaches, where video analysis of the opponent was not as prominent. In all cases, coaches expected the players to persist with applying plan A, and viewed opting to use a plan $\mathrm{B}, \mathrm{C}$ or $\mathrm{D}$ as a potential risk for losing player buy in or surrendering to the opposition. For example, John (u18 coach) outlined how "sometimes you do need a plan B, but normally it detracts from plan A, and actually you don't end up performing plan A to the best of its ability." Similarly, another coach questioned why coaches would even consider a plan B:

"I don't see why you'd give up on it, at this age, when you're talking about development... Why you'd give up on the first initial strategy... are you solving the problem by just like parking it and just saying, you weren't very good at that, so we'll change it a little bit to then something we are good at" (Craig, u13 coach).

\section{Players as problem solvers}

Two lower order themes were generated here: game management and dealing with change. In the case of game management, this referred to recognizing and responding appropriately to the state of the game (e.g., time left, score, weather conditions, and players on cautions or sent off). Coaches from all age phases used scenario based practices to help players develop their game management skills, e.g., "it's the last ten minutes, you're two-one down, what are you going to do...But the players see it as a fun, as a situation where they're being tested, they're playing a game." (Jeff, u11 coach). This perspective was echoed by Rod (u13 coach) who described how "we do scenario-based coaching, in terms of you are two-one down against a team playing three-five-two, how are you going to deal with that? Because that's a pressurized environment and you do see them do different things when it's pressurized." 
Running Head: STRATEGIC UNDERSTANDINGS FOR SOCCER

Coaches of all age phases practiced game management within their competitive

419 games program and suggested that the score line should impact how the team play. For

420 example, Craig (u13 coach) said "particularly in tournaments, we do it quite a bit.

421 So...playing against Arsenal, started off high pressing, got a couple of goals, boys mid 422 game had the understanding...like had the confidence to change the playing style." In 423 the foundation phase, coaches also appeared to encourage helping players to manage 424 games, as long as it was not the only focus: "If your sole purpose is always to win, then finding a way of winning is the most important thing. If your sole purpose isn't just to win but also to educate and learn about a particular way of playing, then this is probably more acceptable." (Matt, u9 coach).

Jaiden (u10 coach) also explained that winning and learning have the potential to go hand in hand: you ever get away from the fact that football, you try and, like you are trying, that's why you're learning... because you're trying to win." (Jaiden, u10 coach).

434 In relation to the second lower order theme, the need for players who can deal with 435 change relates to the game of soccer being an open and complex system, where no game 436 can ever be the same. All coaches agreed that the game of soccer is based upon outwit437 ting the opposition, as such it was common for coaches across the age phases to discuss 438 the need for tactical decision makers who base their decisions on the opponent, e.g., "I 439 think for me, tactical would be...that can change from time to time depending what 440 opposition you're up against." (Ray, u18 coach). The dynamics of tactical decision 441 making was also summed up by Mark (u14 coach): 
Running Head: STRATEGIC UNDERSTANDINGS FOR SOCCER

"I mean there's individual tactics, so 'how am I going to beat my direct opponent?' Or 'how am I going to deal with my direct opponent?' And then there's the team emphasis of 'what do we do as a team when we've got the ball or we haven't got the ball?"’

When coaches referred to the need to adapt to the opposition's actions, it was from a tactical problem-solving viewpoint with no reference to the need for players to monitor their progress in solving this problem or refer back to the team playing style, or the SMM for performance. Furthermore, over half of the YDP and PDP coaches stated that players' solutions to tactical problems was often limited by their technical capabilities. From a perspective of strategic understanding, players must be aware of what they can and cannot do, but also be prepared to control the way in which they interact with other sources to shape not just what they do, but how they think about what they do. For example, David (u16 coach) said "I think your tactics is determined by what you can do and what you can execute. Again, as I said before I still think that their technical ability determines your tactical decisions." Ray (u18 coach) also suggested that strong technical ability can open up a wider range of options for players when seeking to outwit the opponent:

"You know you've got to have the tools in the box to execute those decisions. So, I see sometimes, I watch games and people go, oh bad decision, and I will go in my head, bad technique, because I see, no, you haven't got the tools in the box to make that decision."

Player reflection

Performance analysis technology was considered a necessary support mechanism by all coaches for developing players' ability to reflect on and in performance. Generally, coaches from the youth development and professional development phases 


\section{Running Head: STRATEGIC UNDERSTANDINGS FOR SOCCER}

described engaging with match footage post performance as a sign of a reflective player who can appreciate the tactical elements of game play. However, coaches across the age phases also suggested that players are not particularly skilled with reflection "on" or "in” action e.g., "as I said, in most cases...I don't think they reflect particularly accurately" (Craig, u13 coach). Nevertheless, the coaches explained the potential of performance analysis tools to support reflection on action:

"It's about being able to really begin to question some of those assumptions that a player had about what it was and why they thought it worked. I think that's where we also use analysis quite effectively from an individual perspective" (Tim, u15 coach).

Dean (u16 coach) agreed, suggesting:

"You also get access to match analysis, like I say, every game is filmed...so the amount of learning and reflection you can do about the problems you face, how you solve them and what you may have done differently."

The next lower order theme (having a why behind game actions) relates to situations where players can verbally explain the proposed consequences of game actions, thus raising questions concerning the relationship between knowing and doing for soccer performance. Age and stage of learning is likely to impact this finding due to social and cognitive maturation processes- This is also significant because how and whether games players make decisions in a conscious way is not definite. In naturalistic and dynamic settings for sport, time pressure is proposed as a reason why unconscious and implicit processes for decision making are unknown, and that many verbal reports on conscious and explicit decision making focus on the reasons behind a decision, or the product of a decision (Raab, 2003). On the basis of evidence presented earlier we would challenge this. For the moment, however, it is important to state that the expression of 


\section{Running Head: STRATEGIC UNDERSTANDINGS FOR SOCCER}

declarative knowledge to justify actions is not necessarily an indicator for skilled performance (Allard, Deakin, Parker, \& Rodgers, 1993), but does signify a degree of strategic thinking-

These issues notwithstanding, coaches explained how players might be able to execute certain techniques, skills or tactics; however, it was not often that a player could explain "why" these actions would have an effect on game play:

"That's the biggest thing I think with the youngsters these days, we're trying to get the 'why' out of them...They can all come up with a suggestion of keep the ball in the corner, but as soon as you ask them 'why,' they're like, 'well?'...they need more, they need another layer to their knowledge almost" (Rod, u13 coach).

"I think if players have that sort of menu in their head, and think...well if this situation, this dictates this, I will execute this then. I don't know, I think a deeper understanding can give you a bit more strings to your bow so to speak..." (Jeff, u11 coach).

\section{Individuals within a team}

This higher order theme incorporated two lower order themes. Playing to strengths refers to individual players and the team having an appreciation of their capabilities, in order to outwit the opponent. Coaches from all age phases noted that their most effective players were those who could make decisions in game play based upon their individual skill sets. For example, Sol (u18 coach) explained that "it's not so much that they've got the best technique, they make the best decisions related to their technique." Jeff (u11 coach) also noted that "the difference between the top players I've seen in our academy so far and the weaker ones is that the top ones are comfortable talking about their strengths and weaknesses," while John (u18 coach) was adamant 


\section{Running Head: STRATEGIC UNDERSTANDINGS FOR SOCCER}

that "the top players do that, they look at themselves, they look at where their capabilities are at and how they can reinvent or still affect the game, but maybe it looks a little bit different."

The second lower order theme was recognizing opportunities to practice individual targets, which referred to circumstances where individual players are challenged to enhance an aspect of their play, within a team framework. Coaches emphasised the difficulty for measuring individual player progress according to their target due to the fact they are operating within an environment (the game of soccer) where success is often dependant on how others perform. Interestingly, this was only raised by YDP and PDP coaches, who explained that individual targets can impact the team's performance. For example, Dean (u16 coach) said 'I don't know if we maybe create a little bit of selfishness because we're encouraging everybody to think about their own targets, what they need to get better at, what their strengths, what their weaknesses are etc." In the YDP phase, Craig (u13 coach) also explained how he concentrates on coaching players to improve upon individual targets:

"We'll just play 11-v-11 and then just working with units, so we're just working with individuals, and a lot of the time we're not really overly fussed by the strategy, it's more, we're more working with players on their targets."

Nonetheless, coaches from all age phases expressed how they feel responsible for developing individual players and developing a high-quality team, with little or no emphasis places on the need for players to monitor their own progress with individual challenges or team goals. Sol (u18 coach) suggested that "we're going to get the very best out of you, we're going to maximize everything you've got, but you still want the team to perform as well." Similarly, Jeff (u11 coach) observed that "there's two coaches, probably to sixteen players, how do you affect each individual, their needs, 


\section{Running Head: STRATEGIC UNDERSTANDINGS FOR SOCCER}

whilst obviously maintaining the team element as well," while Kai (u14 coach) said "it's a team sport comprising of individuals that need to work together...in my opinion, each one of them, you're their personal football coach."

\section{Discussion}

\section{The role of strategic understanding}

The primary purpose of this study was to explore coaches' interpretations of game understanding, with a particular emphasis on the role of strategic understanding. Our findings suggest that strategic understanding of the game was inconsistently comprehended between coaches and furthermore, not explicitly coached at any age phase. Thus, there were no universal methods to coaching strategy described by the participants, either across level or club. As in the academic literature to date, tactical decision making and tactical awareness appear to dominate coaches' approaches on what and how to coach game understanding (Kinnerk, Harvey, MacDonncha, \& Lyons, 2018; O’Connor, Wardack, Goodyear, Larkins, \& Williams, 2018). Some coaches suggested that they did develop players' game understanding away from the soccer field (i.e., in the classroom) when preparing for competition; predominantly through use of video analysis with deductive questioning. However, motor performance studies would advise that such an approach toward learning provides limited opportunity to foster the declarative- procedural relationship (Allard, Deakin, Parker, \& Rodgers, 1993) and thus opportunity for players to think strategically via conditional knowledge bases are under facilitated.

Most of the coaches in the current study explained that players are not encouraged to change how they play during competition unless directed to do so by the coach (which is only likely occur during a competitive match where teams are seeking to win points). In the oldest age phase, coaches explained how it was a necessity for the whole 


\section{Running Head: STRATEGIC UNDERSTANDINGS FOR SOCCER}

team to believe in the game plan, therefore changing that plan might lead to the coach being viewed as "weak." In professional soccer in England, clubs have a distinct playing style which is implemented throughout the club's youth system, thus promoting a view of game understanding which requires players to learn and apply key patterns of play (i.e., "if they do this, we do that"). A playing style that denies players an opportunity to alter their tactical decisions and strategic direction on a global and partial level, both in practice and competition might not be conducive to development of a team or individuals with strategic understanding.

Although the coaches in the current study were reluctant to facilitate the opportunity for players to think strategically in game play, it was surprising to note that all coaches also acknowledged the game as a complex system, where players are required to adapt to the range of scenarios that the game poses, which is representative of an ecological perspective of games (Davids et al, 2013). The current findings also reveal conflicting ideas from practice to theory concerning the role of player adaptability and player flexibility. Notably, effective strategic understanding of games includes flexibility of thought during the event itself, where the player applies a number of criterions to a live, in-game play situation, in order to detect an optimum solution. This, we suggest, demonstrates a "flexible performance capability" (Perkins, 1993, p.40), where judgement of an action is dictated by the extent to which it might impact upon the opponent. Importantly, however, being flexible is not the same as being adaptable, in that the judgement of a decision to act is not a behavioural response based upon interacting information that elicits an adaptation to the body in order to apply an efficient movement solution (Davids, Handford, \& Williams, 1994). In fact, we argue that judgement to act is based upon controlled combinations of declarative, procedural and conditional 


\section{Running Head: STRATEGIC UNDERSTANDINGS FOR SOCCER}

591 knowledge (Weinstein \& Van Mater Stone, 1993) about the game and the players play-

592 ing the game, with intention to set a difficult problem (and monitor the progress of this

593 problem response) for the opposing team or player(s). This is because team sport games

594 facilitate a continuous oppositional relationship between the teams playing it, and ac-

595 tions must therefore be understood in their entirety (Grehaigne, Richard, \& Griffin, 596 2005) with individual confrontation, tactical principles and anticipatory situations con597 sidered by and of players.

598

600

601

602

603

606

607

608

609

610

611

\section{Methods used to coach game understanding}

In the current study, the decompartmentalisation of declarative ("know why/why not," Price et al., 2019) and procedural ("know-how-to-because," Price et al., 2019) knowledge bases is similar to previous studies that have examined players' game understanding and performance (Grehaigne \& Godbout, 1998; Turner \& Martinek, 1999; Pritchard, Hawkins, Weigan, \& Metzler, 2008; Kannekens, Elferink-Gemser, \& Visscher, 2009; Harvey et al, 2010). Coaches described the struggle to judge the extent to which players need to know about the game's rules, optimum technical actions, and capabilities of those playing the game (declarative knowledge), in comparison to the extent to which players' need to have the tactical understanding of selecting an appropriate action during game play (procedural knowledge). This dilemma in itself suggests that coaches are unsure to which the role of implicit unconscious responses (ecological), explicit conscious decisions (cognitive) affect "understanding." Furthermore, we note that the coaches did not refer to the role of conditional knowledge bases, which is the understanding of how and when to combine declarative and procedural knowledge (metacognitive) (“know-how-to-learn,” Price et al., 2019). As discussed previously, in the context of games, conditional knowledge suggests a deep understanding of the game and relates to demonstration of three specific metacognitive game skills: deliberate 


\section{Running Head: STRATEGIC UNDERSTANDINGS FOR SOCCER}

thinking and action; meta-level problem solving, and good learners and good teachers (see Price et al., 2019 for a more detailed overview of metacognitive game skills and their relationship to coaching games).

The general consensus from coaches in the current study suggests that players at this level must recognise the state of the game (e.g., score, time remaining, intention of the opponent), the skill sets of players playing the game (opponent, team mates, self), and act accordingly (i.e., tactical appreciation). The coaches did not refer to instances where they encourage or identify instances where players think about how they are thinking about how to set or solve a problem. Despite the fact that games often present high pressured situations where time for conscious reflective cognition and pre reflective cognition is limited (Light, Harvey, \& Mouchet, 2014), we argue that even following actions where there is no time to think, all actions should be self-monitored and therefore justifiable if players are to demonstrate a deep understanding of the game. Thus, supporting the coaches' perspectives from this study, which suggested exceptional game understanding is associated with players who are able to articulate "why" they executed a particular action. However, extent of conscious action for games players is yet to be determined, and it's process remains unclear (Macquet, 2009), thus indicating a need to investigate how games players approach problems during game play. The findings in the current study suggest that soccer curriculums are intensively focussed upon coaching to develop players' individual capabilities, with little emphasis on how the opponent influences players' thinking and actions during both practice and competition. A practical example of this, consistently discussed by coaches, was the process of setting players individual specific challenges to achieve during game play, which were dependant their personal strengths or areas for development. This approach to curriculum design differs from contemporay constructivist ideas of curriculum 


\section{Running Head: STRATEGIC UNDERSTANDINGS FOR SOCCER}

641 design (cf. Bruner, 1960) that suggest that the curriculum progressively "construct"

642 independent self-regulated leaners using progressive complex, from simple to complex

643 design where authentic problems (in a soccer context, problems that consider the oppo-

644 nent) can be revisited in more complex ways using problem solving discovery learning.

645 This is where the player(s) decides on necessary skills, tactics or strategies to deploy,

646 despite what areas they need to personally practice. Furthermore, the coaches suggested

647 that by focusing on "ourselves" the coach and their team are more likely to cause the

648 opponent problems, and consequently outwit the opponent. Coaching a team to focus

649 on individual and team strengths or goals, rather than the actions of the opponent is in

650 contrast to an ongoing "oppositional relationship" for sport (Grehaigne, Godbout, \&

651 Bouthier, 1999; Grehaigne, Richard, \& Griffin, 2005) where actions of the opponent

652 inform momentary tactical decisions in an effort to find a way to win the game (Al-

653 mond, 1986). Our findings are consistent with other empirical studies, where youth

654 soccer coaches prioritize technique or skill practice using deduced principles of game 655 play (Ford, Yates, \& Williams, 2010; O’Connor, Larkin, \& Williams, 2018), before 656 supporting players to enhance their in-action psychological skills (i.e., outwitting the 657 opponent by responding to the opponent using metacognitive game skills).

658 The coaches in the current study expressed a concern that concentrating on the 659 opponent's capabilities to inform players' actions might be considered as a short-term 660 performance driven or a winning focused approach to player development. Therefore, 661 coaches and coach developers may need to ascertain a sense of "comfortableness" with 662 using the opponent as a key influencer for developing deep understanding by determin663 ing imminent in-game actions and rationalizing past in-game actions. In contrast to pre664 vious conceptual work in game understanding (e.g., Grehaigne et al., 1999; Grehaigne 665 et al., 2005; Grehaigne et al., 2005), we suggest that strategy should be purposefully 


\section{Running Head: STRATEGIC UNDERSTANDINGS FOR SOCCER}

666

667

668

669

670

671

673

674

675

676

677

678

680

681

682

683

684

685

686

687

688

689

690

altered as play emerges (and is therefore not just formulated on a macro level when there is ample time available to think). In this sense, there is a need to think strategically about the strategy, tactics and skills deployed, because games are about finding ways to gain advantage and to disadvantage the opponent. It is not logical to dismiss the opponent when thinking strategically if we understand games to be an ongoing episode of "outwitting the opponent," nor is it helpful for player understanding if the coach controls all thinking relating to how their team will play, and why their team will play in this way. By preparing players in practice and providing players with opportunity in matches to think metacognitively, team's will be more capable of independently outwitting their opponent. This is because they will have opportunity to learn how to monitor their own progress in game play and make appropriate adjustments according to what they know and how they think about the opponent, themselves and team mates, the game, how they learn best, and the performance goal. However, in the absence of high-quality scouting information and as an essential skill to be developed, we highlight metacognition as something which appears to be missing in the current diet for players at our sample academies.

\section{Conclusion}

The findings of the current study suggest that professional youth soccer coaches in England share inconsistent interpretations of a player who has a strategic understanding of the game. None of the coaches interviewed purposefully set out to coach their players' strategic understanding of the game, neither in practice nor competition. The findings also highlight that there is no common coaching method used by the coaches to develop their strategic understanding, although coaches appeared to agree on the skills that demonstrate players' superior game understanding (e.g., reflection, game management, justification of game actions, adaptability and playing to strengths). To 


\section{Running Head: STRATEGIC UNDERSTANDINGS FOR SOCCER}

691

693

695

696

698

699

700

701

702

703

704

705

706

707

708

709

710

711

712

713

714

715

\section{1}

\section{2}

\section{3}

\section{5}

add, the coaches viewed metacognitive game skills as valued aspects of player performance, so long as the coach retained some level of control over what and how the players are thinking and acting during game play.

If coaches believe that a "deep understanding" of the game is an important aspect of player performance, then we advise that key decision makers within professional soccer clubs and their coaching staff should work collaboratively to establish a player development program that also aims to foster their players' metacognitive game skills. Due to strategy being a construct inherent in all games, it is logical to advise for coaches to plan opportunities for players to improve their strategic understanding of the game and to trial coaching methods that seek to deliver this benefit for player learning and performance. There are understandable social and cultural barriers within professional sports coaching contexts concerning choices of what, how and why to coach. Therefore, integrating the development of metacognitive game skills into the coaching curriculum will require ongoing and context specific support for coaches.

(1)

(1)

07

8

9

\section{0}

\section{4}


Running Head: STRATEGIC UNDERSTANDINGS FOR SOCCER

\section{References}

Abraham, A., \& Collins, D. (2011). Taking the next step: Ways forward for coaching science, Quest, 63, 366-384.

Allard, F., Deakin, J., Parker, S., \& Rodgers, W. (1993). Declarative knowledge in skilled motor performance: By product or constituent? In J. L. Starkes \& F. Allard (Eds.), Cognitive issues in motor expertise (pp. 95-107). Amsterdam: Elsevier Science.

Almond, L. (1986a). Primary and secondary rules in games. In R. Thorpe, D. Bunker, \& L. Almond (Eds.), Rethinking games teaching (pp. 73-74). Loughborough, England: Loughborough University of Technology.

Braun, V., \& Clarke, V. (2013). Successful qualitative research: A practical guide for beginners. London: Sage.

Bruner, J. S. (1960). The Process of education. Cambridge, Mass.: Harvard University Press.

Dail, T.K. (2014). Metacognition and Coaching: How to Develop a Thinking Athlete. Journal of Physical Education, Recreation \& Dance, 85(5), 49-51.

Davids, K., Araujo, D., Vilar, L., \& Renshaw, I. (2013). An ecological dynamics approach to skill acquisition: Implications for the development of talent in sport. Talent Development and Excellence, 5, 21-34.

Davids, K., Handford, C., \& Williams, A. M. (1994). The natural physical alternative to cognitive theories of motor behaviour: An invitation for interdisciplinary research in sports science? Journal of Sports Sciences, 12, 492-528.

Ertmer, P., \& Newby, T. (1996). The expert learner: Strategic, self-regulated and reflective. Instructional Science, 24(1). 1-24.

Ford, P. R., Yates, I., \& Williams, A. M. (2010). An analysis of practice activities and 
Running Head: STRATEGIC UNDERSTANDINGS FOR SOCCER

instructional behaviours used by youth soccer coaches during practice: Exploring the link between science and application. Journal of Sports Sciences, 28, $483-495$.

Giske, R., Rodahl, S.E., \& HØigaard, R. (2014). Shared Mental Task Models in Elite Ice Hockey and Handball Teams: Does It Exist and How Does the Coach Intervene to Make an Impact? Journal of Applied Sport Psychology, 0, 1-15.

Gratton, C., \& Jones, I. (2004). Research Methods for Sport Studies. London: Routledge.

Grehaigne, J. F., \& Godbout, P. (1995). Tactical knowledge in team sports from a constructivist and cognitivist perspective. Quest, 47, 490-505.

Grehaigne, J.F., Bouthier, D., \& David, B. (1997). Dynamic-system analysis of opponent relationships in collective actions in soccer, Journal of Sports Sciences, 15(2), 137-149.

Grehaigne, J. F., \& Godbout, P. (1998). Formative Assessment in Team Sports in a Tactical Approach Context. Journal of Physical Education, Recreation \& Dance, 69, 46-51.

Grehaigne, J. F., Godbout, P., \& Bouthier, D. (1999). The foundations of tactics and strategy in team sport. Journal of Teaching in Physical Education, 18, 159174.

Grehaigne, J. F., Godbout, P., \& Bouthier, D. (2005). The Teaching and Learning of Decision Making in Team Sports. Quest, 53, 59-76.

Grehaigne, J. F., Richard, J. F., \& Griffin, L. (2005). Teaching and Learning Team Sports and Games. New York, NY: RoutledgeFalmer.

Harvey, S., Cushion, C. J., Wegis, H. M., \& Massa- Gonzalez, A. N. (2010). Teaching games for understanding in American high-school soccer: a quantitative data 
Running Head: STRATEGIC UNDERSTANDINGS FOR SOCCER analysis using the game performance assessment instrument. Physical Education and Sport Pedagogy, 15, 29-54.

Kannekens, R., Elferink-Gemser, M. T., \& Visscher, C. (2009). Tactical skills of world-class youth soccer teams, Journal of Sports Sciences, 27, 807-812.

Kinnerk, P., Harvey, S., MacDonncha, C., \& Lyons, M. (2018). A Review of the Game-Based Approaches to Coaching Literature in Competitive Team Sport Settings, 70, 401-418. Quest.

Light, R. L., Harvey, S., \& Mouchet, A. (2014). Improving 'at-action' decision-making in team sports through a holistic coaching approach. Sport, Education and Society, 19, 258-275.

Lincoln, Y. S., \& Guba, E. G. (1985). Naturalistic Enquiry. Beverley Hills, CA: Sage.

MacIntyre, T.E., Igou, E.R., Campbell, M.J., Moran, A.P., \& Matthews, J. (2014). Metacognition and action: a new pathway to understanding social and cognitive aspects of expertise in sport. Frontiers in Psychology, 5(1155), 1-12.

Macquet, A.C. (2009). Recognition Within the Decision-Making Process: A Case Study of Expert Volleyball Players. Journal of Applied Sport Psychology, 21, 64-79.

McPherson, S. L. (1993). Knowledge representation and decision making in sport. In J. L. Starkes \& F. Allard (Eds.), Cognitive issues in motor expertise (pp. 159188). Amsterdam: Elsevevier Science Publishers B.V.

Memmert, D. (2006). The effects of eye movement, age, and expertise on in-attentional blindness. Consciousness and Cognition, 15, 620-627.

O’Connor, D., Larkin, P., \& Williams, M. A. (2018). Observations of youth football training: How do coaches structure training sessions for player development? Journal of Sports Sciences, 36, 39-47. 
Running Head: STRATEGIC UNDERSTANDINGS FOR SOCCER

791

792

793

794

795

796

797

798

799

800

801

802

803

804

805

806

807

808

809

810

811

812

813

814

815

O’Connor, D., Wardak, D., Goodyear, P., Larkin, P., \& Williams, M. (2018). Conceptualising decision-making and its development: A phenomenographic analysis. Science and Medicine in Football, 2, 261-271.

Perkins, D. (1993). Teaching for understanding. American Educator: The Professional Journal of the American Federation of Teachers, 17, 28-35.

Pill, S. (2014). Informing game sense pedagogy with constraints led theory for coaching in Australian football. Sports Coaching Review, 3, 46-62.

Premier League (2011). Elite Player Performance Plan (EPPP). Retrieved from https://www.goalreports.com/EPLPlan.pdf

Price, A., Collins, D., Stoszkowski, J., \& Pill, S. (2017). Learning to play soccer: Lessons on meta-cognition from video game design. Quest, 70, 321-333.

Price, A., Collins, D., Stoszkowski, J., \& Pill, S. (2019). Coaching games: Comparisons and contrasts. International Sport Coaching Journal, 6(1), 126-131.

Pritchard, T., Hawkins, A., Wiegand, R., \& Metzler, J. N. (2008). Effects of two instructional approaches on skill development, knowledge, and game performance. Measurement in Physical Education and Exercise Science, 12(4), 219236.

Raab, M. (2003). Decision-making in sports: Influence of complexity on implicit and explicit learning. International Journal of Sport Psychology, 1, 406-433.

Richards, P., Collins, D., Mascarenhas, D. R. D. (2016). Developing team decision making: a holistic framework integrating both on-field and off-field pedagogical coaching processes. Sports Coaching Review, 6, 57-75.

Smith, B., \& McGannon, K. R., (2017). Developing rigor in qualitative research: Problems and opportunities within sport and exercise psychology, International Review of Sport and Exercise Psychology, 11, 101-121. 
Running Head: STRATEGIC UNDERSTANDINGS FOR SOCCER

816 Stoszkowski, J., Collins, D., \& Olsson, C. (2017). Using shared online blogs to structure and support informal coach learning. Part 2: The participants' view and implications for coach education. Sport, Education and Society, 22, 407-425.

Tishman, S., \& Perkins, D. (1995). Critical thinking and physical education. Journal of Physical Education, Recreation \& Dance, 66, 24-30.

821 Toering, T. T., Elferink-Gemser, M. T., Jordet, G., \& Visscher, C. (2009). Self-regulation and performance level of elite and non-elite youth soccer players. Journal of Sports Sciences, 27, 1509-1517.

824 Toner, J., Montero, B.G., \& Moran, A. (2015). Phenomenology and the Cognitive Sciences, 14(4), 1127-1144.

826 Toner, J. (2017). Habitual Reflexivity and Skilled Action. Body \& Society, 23(4), 326.

Tracy, S. J. (2010). Qualitative quality: Eight 'big-tent' criteria for excellent qualitative research. Qualitative Inquiry, 16, 837-851.

830 Turner, A. P., \& Martinek, T. J. (1999). An investigation into teaching games for understanding: Effects on skill, knowledge, and game play. Research Quarterly for Exercise and Sport, 70, 286-296.

833 Wade, A. (1967). The F.A. guide to training and coaching. London: Heinemann.

834 Weinstein, C.E., \& Van Mater Stone, G. (1993). Broadening our conception of general education: The self-regulated learner. New Directions for Community Colleges 21(1): 31-39. 